EGU21-14453

https://doi.org/10.5194/egusphere-egu21-14453

EGU General Assembly 2021

(C) Author(s) 2021. This work is distributed under

the Creative Commons Attribution 4.0 License.

\title{
Sea-level rise driven soil salinization
}

\author{
Hannes Nevermann ${ }^{1}$, Amir AghaKouchak ${ }^{2}$, and Nima Shokri ${ }^{1}$ \\ ${ }^{1}$ Institute of Geo-Hydroinformatics, Technische Universität Hamburg, Hamburg, Germany (hannes.nevermann@tuhh.de) \\ ${ }^{2}$ Department of Civil and Environmental Engineering, University of California, Irvine, California, USA
}

Sea level rise (SLR) is a well-documented aspect of anthropogenic climate change which is primary due to the thermal expansion of seawater and melting of ice caps and glaciers (1). Climate change is expected to exacerbate sea-level rise within the next century, much larger than the observations since the beginning of the recordings. Next to various natural hazards and extreme environmental events such as flooding, the sea level rise poses serious long-standing and possibly irreversible consequences on human timescales in coastal regions. For example, soil salinity is expected to increase near shorelines due to sea level rise. Soil salinization, referring to excess accumulation of salt in soil, is a global problem (2) adversely affecting many environmental and hydrologic processes such as terrestrial ecosystem functioning, water cycle and biodiversity. SLRs shift the saltwater-freshwater boundary in coastal regions which will increase the risk of soil salinization further inland. Considering the growing population living in coastal regions, SLR-driven soil salinization has a severe socio-economic impact posing significant threat to farmlands, wetlands, coastal marshes, forests and other ecosystems. Motivated by the importance of the interaction between SLR, climate change and soil salinization, this study aims to determine how the saltwaterfreshwater interface moves under different Representative Concentration Pathways (RCP) scenarios in coastal regions. Groundwater data of coastal wells, Digital Elevation Model's and satellite images will be used to highlight areas under high risk of soil salinization. The results will enable us to quantify the possible extent of the soil salinization as a result of SLR under different climate scenarios with the associated socio-economic consequences. Such information could support decision making and sustainable resource management under different RCPs.

1. Moftakhari H.M., Salvadori G., AghaKouchak A., Sanders, B.F., Matthew, R.A. (2017). Compounding Effects of Sea Level Rise and Fluvial Flooding. Proc. Nat. Acad. Sci., 114 (37), 9785-9790.

2. Hassani, A., Azapagic, A., Shokri, N. (2020). Predicting Long-term Dynamics of Soil Salinity and Sodicity on a Global Scale. Proc. Nat. Acad. Sci., 117 (52) 33017-33027. 